\section{Exercise Induced Rhabdomy- olysis or Acute Compartment Syndrome? A Strong Case for Compartment Pressure Measurement}

\author{
Eldessouky $A^{*}$, Robbins S and Hay SM \\ Department of Trauma and Orthopaedics, Royal Shrewsbury Hospital, UK
}

\begin{abstract}
Several cases have been reported on exertional rhabdomyolysis, most of which involved strenuous activities such as military training, weight lifting, and marathon running.

A 36 year old male who presented with severe pain and swelling of his upper arms bilaterally following an intensive upper body exercise involving pull-ups. This exercise was part of his routine fitness regime. He reported having typhoid vaccine 24 hours following the exercise session. The clinical picture was significant to the extent that compartment syndrome was a serious differential diagnosis and had to be excluded by pressure measurement. He had an elevated Creatine Kinase (CK) of 156000 IU/L and positive myoglobinuria. Patient responded well to intravenous hydration.

This is a case of exertional rhabdomyolysis that developed in a fit and well patient following his routine exercise. The severity of the symptoms as well as the significantly high levels of CK did raise questions regarding the influential effect of typhoid vaccine.
\end{abstract}

\section{Introduction}

Rhabdomyolysis is a severe condition that is caused by muscle breakdown and is often complicated (in $30-80 \%$ of cases) by acute renal failure [1]. The pathophysiology of Rhabdomyolysis induced AKI is believed to be triggered by myoglobin as the toxin causing renal dysfunction [2].

Exertional rhabdomyolysis occurs 24-48 hours following strenuous exercises and usually presents with muscle pain and weakness [3]. Prompt recognition and treatment, including vigorous hydration, is mandatory to avoid rapid clinical deterioration and potential development of acute renal failure [4].

Exercise induced compartment syndrome can cause disastrous consequences if left undiagnosed and treated. Careful clinical

\footnotetext{
*Corresponding author: Amr Eldessouky A, SpR Trauma and Orthopaedics, Alexandra Hospital, Redditch, UK, Tel: +44 1215741676; +44 7462223365; E-mail: amr_rbcs@yahoo.com
}

Citation: Eldessouky A, Robbins S, Hay SM (2016) Exercise Induced Rhabdomyolysis or Acute Compartment Syndrome? A Strong Case for Compartment Pressure Measurement. J Orthop Res Physiother 2: 022.

Received: 21, March 2015; Accepted: 28, April 2016; Published: 12, May 2016 examination aided with intracompartmental pressure measurement is the cornerstone in diagnosis of compartment syndrome [5].

\section{Case Report}

Our report involves a 36 year old male who presented to the accident and emergency unit at the Royal Shrewsbury hospital complaining of significant pain and swelling of his upper arms bilaterally. It extended into his forearms and on to his chest. The patient was medically fit and well, with no significant past history and was not on any medication. He had no known drug allergies.

He reported that 48 hours prior to his presentation he undertook intensive upper body exercise involving pull ups. This exercise was part of his routine fitness regime. The only other event of note was that he had been given the typhoid vaccine 24 hours following the exercise session.

Clinical examination revealed gross, severe swelling in both upper arms extending distally, beyond the elbow. He was keeping his elbows in marked flexion with obvious restriction of both passive and active elbow extension. There was remarkable pain on palpation and both arms were intact from a neurovascular perspective with clearly palpable radial pulses. Passive stretch of the compartments was also painful.

The initial impression was a possible compartment syndrome. Decision was made to measure the compartments pressure as the clinical findings were not conclusive. The measurement was done using the Stryker Intra-compartmental pressure monitor system and the absolute pressure measurement in all affected compartments fell well within normal range (Table 1). Baseline biochemical investigations are listed in table 2.

\begin{tabular}{|c|c|}
\hline Site & Value \\
\hline Right upper arm (front and back) & $14 \mathrm{~mm} \mathrm{Hg}$ \\
\hline Right proximal forearm (front and back) & $13 \mathrm{~mm} \mathrm{Hg}$ \\
\hline Left upper arm (front and back) & $1 \mathrm{~mm} \mathrm{Hg}$ \\
\hline Left proximal forearm (front and back) & $2 \mathrm{~mm} \mathrm{Hg}$ \\
\hline
\end{tabular}

Table 1: Compartment pressure measurements.

\begin{tabular}{|c|c|}
\hline Marker & Value \\
\hline Creatine kinase & 156000 IU/L (N: 55 to 170 IU/L ) \\
\hline ALT & 248 \\
\hline White cell count & 16 \\
\hline C-reactive protein & 18 \\
\hline Urine & Positive myoglobinuria \\
\hline \multicolumn{2}{|c|}{ Table 2: Biochemical investigations. } \\
\hline
\end{tabular}

An urgent MRI scan was arranged to look for muscle pathology including necrosis and this revealed abnormal signal increase on the T2 weighted images involving; latissimus dorsi, trapezius, biceps and brachioradialis muscles. The scan also demonstrated marked oedema in the subcutaneous fat.

The patient was admitted under the care of the renal physicians for intravenous fluid replacement and close observation with regard to 
development of a compartment syndrome. Over the subsequent four days, the swelling gradually improved and his biochemical markers normalised. He was discharged from hospital to outpatient follow up. His CK level returned to normal (106 IU/L) six weeks post presentation.

\section{Discussion}

Cases of rhabdomyolysis following exhaustive exercise, like marathon running or weight lifting, have been reported [6,7]. The significance of this case is that the patient developed rhabdomyolysis following his routine fitness regime which he has been doing on a regular basis. A review of the literature failed to provide evidence that could correlate between administration of the typhoid vaccine and the patient's clinical presentation.

Risk factors for exertional rhabdomyolysis include; exercising in extremes of heat, humidity or under hypoxic conditions. Rhabdomyolysis due to viral and bacterial illnesses have also been reported. Other predisposing factors include drugs; aspirin, alcohol, statins, ergogenic aids, diuretics, toxins, endocrine disease (diabetes, hypothyroidism) and inherited conditions such as sickle cell trait and McArdle's disease [8-11].

The clinical picture is a triad of muscle pain, weakness and tea coloured urine. In severe cases patients can present with cardiac arrhythmias, secondary to electrolyte imbalance, as well as disturbance in coagulation and disseminated intravascular coagulation [12].

Laboratory results may include increased level of serum Creatine Phosphokinase (CPK) which is a marker for the diagnosis of rhabdomyolysis. CK is a central controller of cellular energy homeostasis. By reversible interconversion of creatine into phosphocreatine, CK builds up a large pool of rapidly diffusing phosphocreatine for temporal and spatial buffering of ATP levels. Thus, CK plays a particularly important role in tissues with large and fluctuating energy demands like muscle and brain [13].

As the patient presented with muscle pain, significant swelling and raised CPK, exertional compartment syndrome had to be excluded. The clinical presentation for an acute compartment syndrome is pain out of proportion to physical exam findings associated with a palpable tense compartment [14]. The surgery required to decompress the involved compartments (fasciotomies) would have been extensive and an emergency undertaking. The window for successful surgical intervention is short yet to miss the diagnosis in this case would have been disastrous resulting in significant functional deficit. In this case given level of clinical suspicion at presentation and the high stakes involved, the use of the pressure measuring device was essential and the decision not to decompress vindicated by his complete recovery [15].

The MRI scan (Figure 1) demonstrated increased signals on the $\mathrm{T} 2$ weighted images. This represents the oedema accompanying the muscular lesions and is not specific to muscular necrosis, as it is also seen in cases of myositis and traumatic muscular lesions [16].

Exercise induced compartment syndrome with Rhabdomyolysis has been reported not only with heavy exercise but also following very short run $[17,18]$.

\section{Conclusion}

This is a case of exercise induced rhabdomyolysis in a young healthy individual following his routine exercise regime. It's

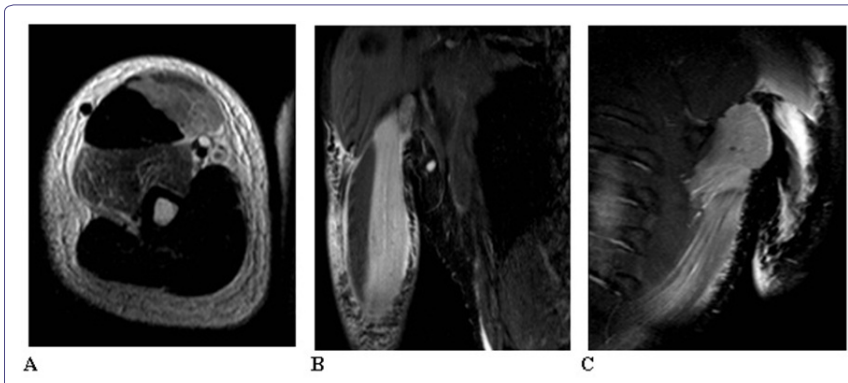

Figure 1: MRI scan showing: 1A: Axial T2 TSE right arm with increased signal in brachialis and short head biceps. 1B: Coronal STIR Right upper arm with increased signal in biceps. 1C: Coronal STIR left upper arm with increased signal latissimus dorsi.

similarity in presentation to compartment syndrome cannot be overstated. Despite the alarming level of CK (156000 IU/L), the patient did not develop compartment syndrome or acute renal failure. Whilst often argued to be a clinical diagnosis, compartment syndrome was excluded by serial clinical assessments in addition to compartment pressure measurement and the authors would suggest that all trauma departments should have this facility. The relevance of the typhoid vaccination could not be confirmed.

\section{References}

1. Sułowicz W, Walatek B, Sydor A, Ochmański W, Miłkowski A, et al. (2002) Acute renal failure in patients with rhabdomyolysis. Med Sci Monit 8: 24-27.

2. Nath KA, Balla G, Vercellotti GM, Balla J, Jacob HS, et al. (1992) Induction of heme oxygenase is a rapid, protective response in rhabdomyolysis in the rat. J Clin Invest 90: 267-270.

3. Sayers SP, Clarkson PM (2002) Exercise-induced rhabdomyolysis. Curr Sports Med Rep 1: 59-60.

4. Zimmerman JL, Shen MC (2013) Rhabdomyolysis. Chest 144: 1058-1065.

5. Shadgan B, Menon M, O'Brien PJ, Reid WD (2008) Diagnostic techniques in acute compartment syndrome of the leg. J Orthop Trauma 22: 581-587.

6. Hikida RS, Staron RS, Hagerman FC, Sherman WM, Costill DL (1983) Muscle fiber necrosis associated with human marathon runners. J Neurol Sci 59: 185-203.

7. Goubier JN, Hoffman OS, Oberlin C (2002) Exertion induced rhabdomyolysis of the long head of the triceps. Br J Sports Med 36: 150-151.

8. Brown TP (2004) Exertional rhabdomyolysis: early recognition is key. Phys Sportsmed 32: 15-20.

9. Zager RA (1996) Rhabdomyolysis and myohemoglobinuric acute renal failure. Kidney Int 49: 314-326.

10. Harrelson GL, Fincher AL, Robinson JB (1995) Acute exertional rhabdomyolysis and its relationship to sickle cell trait. J Athl Train 30: 309-312.

11. Nadaj-Pakleza AA, Vincitorio CM, Laforêt P, Eymard B, Dion E, et al. (2009) Permanent muscle weakness in McArdle disease. Muscle Nerve 40: 350-357.

12. Shani Y, Heled Y, Moran DS (2001) Exercise rhabdomyolysis. Aviat Space Environ Med 72: 856.

13. Schlattner U, Tokarska-Schlattner M, Wallimann T (2006) Mitochondrial creatine kinase in human health and disease. Biochim Biophys Acta 1762: 164180.

14. Hutchinson M (2011) Chronic exertional compartment syndrome. Br J Sports Med 45: 952-953.

15. Stryker (2016) Stryker Intra-Compartmental pressure monitor system. Surgical equipments, Stryker, Kalamazoo, MI, USA.

16. Kakuda W, Naritomi H, Miyashita K, Kinugawa H (1999) Rhabdomyolysis lesions showing magnetic resonance contrast enhancement. J Neuroimaging 9: 182-184. 
Citation: Eldessouky A, Robbins S, Hay SM (2016) Exercise Induced Rhabdomyolysis or Acute Compartment Syndrome? A Strong Case for Compartment Pressure Measurement. J Orthop Res Physiother 2: 022.

- Page 3 of $3 \cdot$

17. Miozzari HH, Gerard R, Stern R, Toman J, Assal M (2008) Acute, exertional medial compartment syndrome of the foot in a high-level athlete: a case report. Am J Sports Med 36: 983-986.
18. Basnet B, Matar M, Vaitilingham S, Chalise S, Irooegbu N, et al. (2016) Exercise-induced acute compartment syndrome in a young man, occurring after a short race. Proc (Bayl Univ Med Cent) 29: 143-144. 